\title{
PUNISHMENT AS THERAPY: A REPLY TO HALLECK
}

\author{
KATHRYN N. JACKSON*
}

\section{INTRODUCTION}

Criminal punishment involves the coercive restraint of individuals by the state, usually through prison confinement and hard treatment. It is therefore a practice in need of moral justification. The two most common arguments of justification focus either on the retributive nature of punishment or on its deterrent effect. According to the retributive view, offenders deserve punishment for what they have done. According to the deterrence theory, punishment is justified to the extent that it deters further crime either by the offender or by others who fear a similar fate. The retributive justification turns on that which has already occurred, namely the violation of law by the individual to be punished. The deterrence theory looks to the future consequences of punishment as the basis for justification. ${ }^{1}$

Both arguments rest on a common assumption about the ability of individuals to control their actions. Retributive and deterrence theorists agree that unless criminals have control over what they do, that is, unless their actions are freely chosen, they are not fully responsible. If they are not responsible for their crimes, criminals cannot be said to deserve punishment, and the retributive theory is without foundation. Furthermore, punishment can have a deterrent effect only on those who are able to conform their behavior to that which is legally required or permissible. Threat of punishment cannot deter those who are unable to refrain from violating the law. Thus the deterrence argument also depends on a condition of responsibility.

In his article, Responsibility and Excuse in Law and Medicine: A Utilitarian Perspective, Seymour Halleck argues that criminals vary in the degree to which they are in fact able to control their actions. ${ }^{2}$ He contends that because they are not fully responsible for what they have done, the standard retributive and deterrence arguments are inadequate to justify the practice of criminal punishment. Furthermore, since degrees of responsibility vary, he regards it as unjust to treat all criminals as if they were equal in this regard. Thus,

Copyright $(\mathcal{1} 1986$ by Law and Contemporary Problems

* Assistant Professor of Philosophy, Duke University.

1. For a more detailed discussion of the retributive and deterrence theories, see M. Goldinc, Philosophy of LAW 69-105 (1975).

2. Halleck, Responsibility and Excuse in Law and Medicine: A Utilitarian Perspective, Law \& ConTEMP. Probs., Summer 1986, at 127, 140. 
Halleck questions the justice of subjecting offenders to determinate sentencing. ${ }^{3}$

Halleck suggests that an adequate response to the problem of criminal wrongdoing can be determined without presupposing the problematic notion of responsibility if a medical model replaces the current penal model.4 Accordingly, he believes that offenders should be regarded as medically ill, not morally evil, and criminality should be viewed "as a condition that can be treated." 5 On Halleck's view, those found by the courts to have committed criminal offenses would be confined and treated against their will, in a way similar to the present civil commitment of psychiatric patients. ${ }^{6}$ The involuntary treatment of criminals requires their confinement. Halleck recognizes that confinement is a form of punishment. ${ }^{7}$ However, he believes that criminals can be punished as long as the punishment can be subsumed under the medical model he describes. ${ }^{8}$

Adopting Halleck's medical model would require abandoning the current practice of fixed sentencing. The courts could not determine in advance exactly how long it would take for therapy to be effective. Only the psychiatrist could decide when the criminal-patient is ready to regain freedom, and this determination could be made only in the course of therapy itself. Halleck argues, therefore, that using the medical model as a response to crime requires open-ended sentencing. ${ }^{9}$ He concludes that determinate sentencing is both unjust and incompatible with the therapeutic ends for which offenders are confined.

Because Halleck is advocating a practice that involves the coercive confinement and treatment of individuals, it is as much in need of moral justification as is criminal punishment. Halleck appeals to utilitarian considerations to justify this practice. He argues that the social good is promoted when dangerous individuals are detained. ${ }^{10}$ Because he believes this consideration is insufficient to justify the coercive treatment of offenders, Halleck also appeals to the overall social benefits that result from treatment. "1 Those treated will presumably comply with the law in the future, which is clearly in the interest of society. The treatment also restores some measure of mental health to the criminal. ${ }^{12}$ To increase the number of individuals who

3. Id. at $140-42$.

4. Id. at 128 .

5. Id. at 143. Others have held a similar view. See, e.g., K. Menninger, The Crime of Punishment (1968).

6. Halleck, supra note 2, at 143 .

7. Id. at 144.

8. Halleck's views regarding responsibility and the medical approach to crime are similar to those of the British penal reformer, Lady Barbara Wooton. Her views are developed in B. Wooron, Social Science and Social Pathology (1959).

9. Halleck, supra note 2 , at $142-45$.

10. Id. at 143 .

11. Id. at 141 .

12. Id. 
are psychologically healthy enhances overall social utility and is thus desirable on utilitarian grounds.

Certain aspects of Halleck's view have an intuitive appeal. His model justifies both the punishment and the rehabilitative treatment of criminals. Therefore, his aproach not only satisfies the widely held conviction that those who violate the law should be punished somehow for what they have done, but it also reflects our belief that in many cases offenders are in need of therapy to help them deal more effectively with their moral, legal, and social responsibilities. This attempt to incorporate two apparently contradictory practices within the medical model is ultimately flawed, however, by the failure to note some fundamental differences between law and medicine. Once these differences are recognized, the alleged significance of the medical model as a response to crime has no force.

This article focuses on four of the most important issues surrounding Halleck's proposal: punishment in law and medicine; the physician as excusegiver; the utilitarian justification of punishment; and the justice of indeterminate sentencing. A consideration of these points provides the basis from which some general observations regarding the nature and justification of criminal punishment will be drawn.

\section{II}

\section{Punishment in Law and Medicine}

Halleck believes that criminals should be punished to the extent that it will further their rehabilitation. He points out that the practice of medicine routinely involves punishment, ${ }^{13}$ and he apparently believes that any case of therapeutic punishment is justified by the medical practice of which it is a part. If the treatment is justified, then any punishment required in the course of that treatment is also justified. To the extent that the punishment received by criminals is consistent with Halleck's model of therapeutic treatment, it is similarly justified.

In describing circumstances in which punishment is a part of therapy, Halleck suggests that any unintended, aversive consequences of medical treatment are a kind of punishment. ${ }^{14}$ This sense of punishment, however, is at best metaphorical. ${ }^{15}$ Only the cases in which punishment is intentionally imposed for the sake of therapy are relevant here.

Halleck contends that therapeutic punishment is common in the treatment of those suffering from "diseases of the will." 16 In some cases, the treatment is based simply on "providing aversive consequences or punishment for the undesired behavior."17 In other words, patients are sometimes subjected to behavioral conditioning as a means of eliminating undesirable behavior they

13. Id. at 138 .

14. Id. at 129 .

15. See M. Golding, supra note 1 , at 70 .

16. Halleck, supra note 2 , at 138.

17. Id. 
would otherwise be unable to control. In the treatment of other psychological diseases, such as anorexia and bulimia, a system of reward and punishment is used to help patients develop greater confidence in their ability to control their own behavior. By gaining a new sense of their abilities, these patients are able to choose less maladaptive behavior. Halleck says little about the treatment he feels criminals should receive. Since he believes they too have difficulty controlling their behavior, criminals also are in need of psychiatric treatment. A primary goal of therapy would be the elimination of the antisocial behavior exhibited by criminals. To the extent that punishment is needed to realize this end, it is as justifiable, from a moral point of view, as any other case of therapeutic punishment of those suffering from a disease of the will.

Halleck argues, however, that there is a punitive, as well as therapeutic, element involved in the involuntary treatment of criminal offenders. He says that when offenders are sentenced to programs such as those he recommends, "some punishment is intended and past criminal behavior is not excused."18 This view is not obviously compatible with the view that criminals are not responsible for their violations of law. If they are not excused for the wrong they have done, then they must be blameworthy. Halleck suggests that they are blameworthy when he argues that nontherapeutic punishment requires a nonutilitarian (or retributive) justification. ${ }^{19}$ This admission is inconsistent with his stated adherence to a utilitarian perspective and with his claim that the notion of responsibility should be abandoned in our social response to crime.

Because Halleck admits that there is a nontherapeutic element to the treatment received by offenders, the propriety of his medical model is called into question. This admission also leaves unjustified this punitive aspect of the therapeutic response to crime. The medical model is, at best, appropriate only with reference to the treatment of criminals. Thus, the punishment of criminals can be justified only by its therapeutic effect. Halleck might believe that the punitive aspect of the punishment received by offenders ultimately serves some therapeutic end; perhaps he thinks it helps teach them that they are responsible (in the sense of culpable) for their actions. However, it is not clear how it could be therapeutically helpful to blame criminals for past actions over which they presumably had no control. In the cases of therapeutic punishment described by Halleck, the punishment is used in response to negative behavior displayed by patients while in treatment; it is not imposed in response to actions taken prior to therapy.

Thus, it appears unlikely that the punitive aspect of the involuntary treatment of offenders can be regarded as therapeutic in nature. The fact that they would be confined and treated against their wills in response to their own wrongdoing introduces an aspect of nontherapeutic punishment that even Halleck's medical model cannot eliminate. Because his model leaves the

18. Id. at 144 .

19. Id. 
nontherapeutic punishment of criminals without either definition or justification, Halleck has yet to show that it is possible to eliminate the notion of criminal responsibility by the adoption of a medical response to crime.

\section{III}

\section{The Physician as Excuse-Giver}

Halleck asserts that, "[m]ost people, including doctors, do not look upon medical practice as a system that provides excuses from blame or obligations." 20 He thinks such a view is mistaken because physicians routinely excuse patients from responsibilities and obligations. Furthermore, he argues that it would be advantageous if the medical model of excuse-giving was adopted by the criminal justice system. ${ }^{21}$ However, Halleck misunderstands the role of the physician in the process whereby patients are excused from blame. This misunderstanding calls into question the plausibility of using a medical model as the basis for our response to crime.

Patients are often excused from their obligations because of a medical judgment regarding their abilities and health status. They are excused from blame for past breaches and from a performance of future responsibilities. In the former case, a physician provides an explanation for the failure to perform in terms of the patient's medical status. In the latter instance, a physician explains why the patient will be either medically harmed by or unable to perform an upcoming obligation. In both cases, the physician's explanation is couched in medical terms.

Although Halleck suggests that physicians have the capacity to excuse patients from their obligations, this assertion is imprecise. Physicians merely determine the medical condition of their patients, and then assess whether this diagnosis is medically sufficient to explain the reason for failing to fulfill a past or future obligation. The important factor that Halleck ignores is that, in most cases, someone other than the doctor determines whether this medical explanation constitutes a sufficient condition for excusing the failure to perform. An excuse is granted only when there is a determination that the medical explanation is sufficient to justify an excuse.

For example, when students obtain a medical excuse for missing an examination, they must first obtain a letter from their physician which explains the health reason for their absence. The relevant authority, such as a dean or professor who is authorized to grant excuses, then reviews this letter. Because excuses are almost always granted for medical reasons, it may seem as if the physician grants the excuse, but he does not. The physician is no more capable of granting an excuse than anyone else not specifically authorized to do so. The doctor merely provides a causal account of the person's behavior; the medical account does not excuse as such. The authorized excuse-giver must evaluate the medical evidence in order to

20. Id. at 130 .

21. Id. at 140 . 
determine whether the agent should be absolved of responsibility. Admittedly, there is no inherent reason why the same person cannot provide the medical account and also determine whether this provides sufficient grounds for an excuse. However, the two roles should not be confused. If the physician does excuse, he does not do so as doctor, but as excuse-giver or judge. Moreover, there is no reason to think that a physician, trained only to make medical judgments, should be authorized to make the normative judgments involved in excuse-granting.

If physicians lack special authority to excuse, even for medical reasons, then Halleck must limit significantly the power of physicians in his proposal to enact a medical response to crime. They could not decide on their own who is to be excused from blame; the courts would make this decision. Similarly, physicians could not determine release dates without the approval of a clearly defined legal authority who would assess the medical evidence presented by the doctors. Such a system resembles current legal practice more than an innovative approach based on a medical model.

There is another important feature of the physician's role in the process of excuse-giving. Halleck argues that physicians have obligations to society over and above those owed to individual patients. To the extent that physicians play a role in the process of excuse-giving, their actions will have social consequences. Halleck mentions cases involving insurance and worker's compensation claims as examples in which the physician has an obligation to both the patient and society. ${ }^{22}$

This notion of a dual obligation underscores the problem that arises when a careful distinction between doctor and excuse-giver is not maintained. Although a doctor's medical judgments may affect societal interests, the physician is primarily concerned with the health and well-being of the individual patient. A physician who sacrifices the good of his patients for the sake of social obligations is someone who also sacrifices his status as a doctor committed to treating the sick.

To whom would the physicians in Halleck's suggested programs owe their primary responsibility? Would they be most concerned with the good of the state for which they work, or with the health of the individual offenders whom they are committed to treat? Suppose a case arises in which the therapeutic needs of the patient indicate release, but the need of society for protection requires continued detention? Physicians would abandon their role as healers to the extent that they chose the latter over the former. There are cases in which society's needs for protection should outweigh the psychiatric needs of individual criminals. However, a society such as ours that values individual freedom could not tolerate a situation in which psychiatric treatment of criminal patients is always mediated by perceived social needs. 


\section{IV}

\section{The Utilitarian Justification of Punishment}

In defending his medical model, Halleck suggests that individual physicians are as concerned with the pursuit of utilitarian ends in the treatment of patients, as is the criminal justice system in its response to criminals. ${ }^{23}$ Although it is true that physicians are concerned with promoting the individual health and well-being of patients, this concern can hardly be called utilitarian. For reasons mentioned above, ${ }^{24}$ physicians abandon the role as doctors to the extent that they pursue the good of society at the expense of the good of individual patients-yet such a concern for overall social utility is a feature of utilitarianism. The doctor who focuses on the good of individual patients may be acting for paternalistic or benevolent reasons, but his actions are quite compatible with both utilitarian and nonutilitarian moralities. Pursuing the good of particular others is neither a sufficient nor necessary feature of utilitarianism.

Halleck also asserts that the practice of medicine and the practice of law both seek to maximize responsibility. ${ }^{25}$ Since utilitarianism is a maximizing theory, the maximization of responsibility would be achieved by the utilitarian perspective if responsibility were a fundamental good to be pursued. It is a mistake, however, to think that the maximization of responsibility is a basic aim of either law or medicine. It is an even greater mistake to think that it is justified in either system by the utilitarian perspective.

There are many cases of psychiatric treatment in which the aim is to teach patients that they can in fact control their behavior. In these cases, the goal of therapy is to elicit in patients the sense that they are responsible for their actions because they have the capacity for choice. Halleck admits, however, that this goal may not be therapeutically indicated in all cases. ${ }^{26}$ Where behavior modification techniques are used, there is no interest in eliciting the patient's capacity for choice. The goal is simply to alter the undesirable behavior through scientific techniques and manipulation. To say that the maximization of responsibility is the aim of psychiatric therapy is an overstatement; responsibility is a goal of treatment only if it is in the patient's best interests.

The kind of responsibility that is the end of therapy should be distinguished from that which is involved in legal judgments. The former refers to the agent's ability to control or choose behavior; it can be referred to as capacity responsibility. The latter refers to one's legal status; it indicates that one can be judged liable, from the legal perspective, for what one has

\footnotetext{
23. Id. at 137 .

24. See supra notes $20-22$ and accompanying text.

25. Halleck, supra note 2, at 137.

26. Id. at 138 .
} 
done. ${ }^{27}$ Legal responsibility, which Halleck rejects, ${ }^{28}$ presupposes capacity responsibility, which he sees as the goal of therapy. (Notice, however, that Halleck occasionally adopts the notion of legal responsibility. For example, his assertion that criminals should be punished for what they have done presupposes legal responsibility. ${ }^{29}$ ) When Halleck argues that responsibility should be maximized, he is referring to capacity responsibility.

However, the maximization of capacity responsibility cannot be the goal of therapy in Halleck's suggested approach to crime. Presumably, there will still be cases in which the scientific manipulation of behavior, through either behavioral conditioning techniques or psychosurgery, is therapeutically indicated. In these cases, the patient will not benefit from any attempt to elicit a sense of responsibility, and the negative behavior can be avoided only through direct manipulation.

Once again there is an apparent conflict between the interest society has in maximizing compliance and the interest the individual has in being free from external control. Although he is not explicit on this point, Halleck seems to believe that the utilitarian perspective favors the former over the latter. For example, he believes that our interest in the elimination of all crime, or in the pursuit of what we might call "social hygiene," justifies the medically oriented approach to crime, even to the extent that behavior can be altered through techniques of behavior modification and psychosurgery. ${ }^{30}$ Halleck sees no moral problem with this sort of manipulation of the individual. Nor does he have any moral objection to identifying potential criminals and locking them up for long periods of time. ${ }^{31}$ His only concern with this practice is that it is currently impractical to do so. His assumption seems to be that practices are justified to the extent that they serve to rid society of criminal activity. On this view, maximizing responsibility cannot be a central goal of the medical treatment provided criminals.

Throughout his article Halleck argues in favor of a scientific approach to crime. He argues, for example, that "no scientific premises would be violated" if criminals were treated as if they were ill, ${ }^{32}$ and he advocates the use of psychosurgery as a means of rehabilitating criminals. Such treatment, he claims, is called for under utilitarian principles ${ }^{33}$ and is made inevitable by scientific progress. He states: "It is only a matter of time before new biological methods of treating crime by altering brain chemistry are available ... . As newer, more efficient and safer technologies develop, pressures for their use in some type of medical treatment approach will be irresistible." 34

27. For a discussion of the distinction between capacity, responsibility, and legal responsibility, see H.L.A. Hart, Punishment and Responsibility: Essays in the Philosophy of Law 215-22, 227 30 (1968).

28. Halleck, supra note 2, at 128 .

29. Id. at 143-44.

30. Id. at 146 .

31. Id. at 142 .

32. Id. at 140 .

33. Id. at 146 .

34. Id. 
There are two responses to this statement. First, scientific possibilities and capacities do not in themselves determine how we ought to act in morally questionable situations. As science develops, new moral problems often emerge. Indeed, the field of medical ethics has developed in response to scientific progress. When discoveries of science violate the dictates of morality-of right and wrong-they should not be pursued. Morality constrains the actions of scientists and physicians just as much as the actions of everyone else. Books and films such as Brave New World ${ }^{35}$ and $A$ Clockwork Orange ${ }^{36}$ warn us of the dangers of science without morality. Unfortunately, Halleck's vision is fully consistent with those depicted in these fictional works, which alone should cause one to pause. In designing social institutions and practices such as those involved in a legal system, it is not enough that we adhere to scientific principles. A defensible conception of the good society cannot be derived from science alone. ${ }^{37}$

Halleck might object that his vision is not at all devoid of a moral framework. Indeed, he sees his medical approach to crime as a link between science and morality. ${ }^{38}$ Halleck embraces the moral theory of utilitarianism, which he believes provides the moral justification for the medical and hence scientific approach to crime. Thus, he assumes that the utilitarian perspective, which entails the medical approach to crime, bridges the gap between science and morality.

If the utilitarian framework does yield the kind of scientific-medical approach to crime suggested by Halleck, then we may seriously question the adequacy of utilitarianism to provide the moral basis for fundamental social institutions such as punishment. Recent criticism of utilitarianism has focused on what John Rawls describes as its failure to "take seriously the distinction between persons." 39 Halleck's views regarding the medical approach to crime illustrate one way in which this failure might manifest itself. He never considers the possibility that individuals have moral rights that place constraints on how others, including the state, can treat them, even where some social good, such as the elimination of crime, would result. Rights to freedom or autonomy would prohibit many of the practices that Halleck thinks are morally unproblematic, such as the legal detention of potential criminals and the use of psychosurgery to eliminate crime. If individuals hold some rights to freedom against the state, then the goal of the criminal justice system cannot be defined simply in terms of the pursuit of social hygiene. Though compliance with law is an important social value, it may be morally impermissible to purchase it at the cost of individual freedom and autonomy.

There are several values that the criminal justice system must balance: social hygiene is one, respect for the autonomy of individuals is another.

35. A. HuXley, Brave New World (1932).

36. A. Burgess, A Clockwork Orange (1962).

37. Fletcher, Ethical Aspects of Genetic Controls: Designed Genetic Changes in Man, 285 New ENG. J. MED. 776 (1971).

38. Halleck, supra note 2, at 146.

39. J. Rawls, A Theory of Justice 27 (1971). 
Contrary to Halleck's suggestion, ${ }^{40}$ the latter is due individuals just because they have certain rights, and not because it may be efficient to grant freedom to individuals. H.L.A. Hart has argued that the current system, in which legal standards are announced and deviations are punished, is one that maximizes freedom. According to Hart, this system presents individuals with the option of "obeying or paying" and offers them the opportunity to plan their lives according to the law's demands. ${ }^{4}$ The freedom of individuals is thus valued along with the good resulting from compliance with the law, but the former takes priority over the latter. A social system that has laws protecting individuals from external control and manipulation does so at the risk of violations. Halleck's view of utilitarianism is one that does not provide individuals with any special protection against that which is necessary for the pursuit of social hygiene; it yields a system in which individuals do not seem to have any rights. It cannot therefore justify a system such as Hart's, which values freedom and protects individuals from interferences that are made just for the sake of social hygiene.

\section{$\mathrm{V}$ \\ The Justice of Indeterminate Sentencing}

Halleck argues that there are three reasons to prefer open-ended sentences over any system in which sentences are more or less fixed. First, the medical model entails the indeterminacy of sentencing; ${ }^{42}$ second, it is more efficient from the utilitarian perspective; ${ }^{43}$ and third, it is more just in terms of non-utilitarian considerations of fairness and equality. ${ }^{44}$ Since two of these have already been considered, the third will now be discussed.

Since punishment involves inflicting some degree of harm on persons, questions of justice often arise. How much punishment should be imposed for the sake of justice? When does a given punishment go beyond what is considered just? What system of punishment is the most fair? For Halleck, a system of determinate sentencing is necessarily unjust in at least two ways. On the one hand, it yields a situation in which individuals who commit the same crime are necessarily punished to varying degrees. Since people respond differently to the same treatment, they will experience differing amounts of pain and suffering from identical sentences. ${ }^{45}$ Because justice requires equal punishment for those who are guilty of the same crime, Halleck argues that indeterminate sentences are more appropriate. Only in this way can punishments be equalized, and hence made just.

40. Halleck, supra note 2 , at 146.

41. H.L.A. Hart, Prolegomenon to the Principles of Punishment, in Punishment and Responsibility: Essays in the Philosophy of Law 1-27 (1968).

42. Halleck, supra note 2, at 143 .

43. Id. at 141 .

44. Id. at 140 .

45. Id. at 141 . 
On the other hand, Halleck argues that it is unjust to impose equal sentences on all who commit the same prohibited act, since individuals vary greatly in their ability to control their behavior. Because legal excuses are rare under the current system, "[t]he mentally defective person and the genius are equally liable if they forge a check." 46 According to Halleck, this practice violates basic principles of justice because those who are unequal in their measure of culpability are held to equal standards. Halleck argues that the appropriate corrective measure involves the replacement of current practice with a system of indeterminate sentencing.

Halleck recognizes that his system may promote injustices of its own. ${ }^{47}$ For example, he might agree that recalcitrant, petty criminals may be incarcerated for much longer than others who have committed more serious crimes but are more malleable. However, he suggests that his system will violate fewer rights, and be more just than the alternative.

It is not at all clear that Halleck is right about this point. Though current practice may well result in many unjust situations, a system of indeterminate sentencing is unjust in theory, while a system of fixed sentencing is not. Consider Halleck's first objection to determinate sentencing. In order to say that identical sentences entail unequal suffering, it is necessary to view the punishment from the perspective of the person punished, and in terms of the experience of punishment. While it is undoubtedly true that there will be significant differences in the way people experience the same sentence, it is not at all clear this fact is relevant from the perspective of justice.

Halleck suggests that, because of the differential in experiences, people will feel that they are treated unequally and hence, unjustly. ${ }^{48}$ Questions of justice, however, are not settled by how people feel about the treatment they receive. Rather, we must adopt an impartial, objective perspective in order to determine questions of justice. ${ }^{49}$ While any efforts made to rehabilitate and treat criminals entail Halleck's purely subjective and individualized approach to criminals, it cannot be central in the context of criminal punishment. As already discussed, our medical status as patients is determined by our particular needs, ailments, and circumstances. Our legal status as citizens is determined by the complex system of rights, duties, and privileges defined by law.

It is thus a requirement of justice that citizens be informed of their legal benefits and burdens. Thus, they must not only be informed of their rights and duties, but they must also have some clear indication of what they can expect when their rights are violated or when they breach their duties. The latter requires that individuals know the nature of the sentence to be imposed

46. Id. at 140 .

47. Id. at $144-45$.

48. Id.

49. J. RaWLs, supra note 39 , at 183-92. 
for the breach of specific legal duties. Indeterminate sentencing, therefore, violates basic assumptions regarding our legal status as citizens. ${ }^{50}$

Halleck might object that we cannot know in advance the nature of a given sanction because we cannot know how we, as individuals, would respond to a given sentence. This objection is based on the assumption that the most salient feature of punishment is the actual pain and suffering experienced.

However, punishment may serve other purposes. Backing criminal laws with specific punishments may serve to express society's view of the relative severity of crimes. Punishment thus has a symbolic or expressive role. ${ }^{51}$ For example, murder carries a more severe punishment than assault because it is a more serious crime. Although in practice it is difficult to work out the relative severity of all crimes and to determine the appropriate system of punishments, the absence of any stated sanctions would leave us without any public indication of which crimes are more serious than others. If one goal of punishment is to indicate the severity of crimes, a system of indeterminate sentencing would undermine this goal. Similarly, the absence of stated sanctions would undermine any educational purpose the law might have. For example, it would be very difficult to convince someone convicted of rape that his crime is more serious than petty theft, if there is not an established policy that calls for punishing the rape more severely than the petty theft. A system of fixed sanctions could serve the therapeutic ends of punishment, therefore, by indicating to the offender the extent to which society condemns certain kinds of behavior. Finally, a system of indeterminate sentencing would compromise the rights of offenders and nonoffenders alike. All citizens should know what is generally expected of them as citizens, but the practice of indeterminate sentencing precludes this knowledge in a fundamental way.

Although the current system may be unjust in particular cases, Halleck's system of open-ended sentencing is fundamentally unjust. The former injustices are a matter of practice, while the latter are a matter of theory. A system of determinate sentencing may not be ideal, but it is clearly preferable to, and more just than, any system of indeterminate sentencing.

\section{VI}

\section{Conclusion}

In conclusion, I must stress that my position does not rule out the effort to rehabilitate criminals. I have argued only against Halleck's view that the primary emphasis of our response to crime should be defined in medical, as opposed to punitive, terms. Halleck's attempt to provide an alternative approach to criminal behavior based on a medical model and grounded on a utilitarian morality fails for several reasons. Halleck has not established the

50. For other arguments against indeterminate sentencing from the perspective of justice, see H.L.A. HART, supra note 41.

51. See, e.g., J. Feinberg, The Expressive Function of Punishment in Doing and Deserving: Essays in THE ThEORY OF RESPONSIBILITY 95 (1970). 
propriety of replacing the legal approach to crime with a medical model, nor has he provided good reasons for adopting a purely utilitarian perspective. Social hygiene may be one goal of a criminal justice system, but we have no reason to assume, as does Halleck, that it alone should determine our response to those who have broken the law. Even if efforts at rehabilitation within the penal system are generally unsuccessful, ${ }^{52}$ as Halleck suggests, we must nevertheless return criminals to their freedom when their term is complete. Such is the price of freedom and of a system that recognizes the rights of citizens.

52. Halleck, supra note 2 , at 142. 
